\title{
TOWN'S REFUSE AS A SOURCE OF SOIL ORGANIC MATTER
}

\author{
By Dr. E. H. TRIPP
}

A LTHOUGH animal and vegetable wastes have been used as manure for untold ages, and their good effect on soil fertility has never been in doubt, chemists and microbiologists would be the first to confess that there are many gaps in our knowledge of their modes of action. To take farmyard manure-still without a rival-we know the value of the plant foods it contains, and its remarkable power, after decomposition, of promoting and conserving the granular structure of the top soil, thereby making it porous to air, absorptive and retentive of moisture. How this physical effect is brought about is still largely a matter of hypothesis ; and generally speaking, we know nothing of the sequence of changes that follow the incorporation of farmyard manure with the top soil.

The solution of such questions would help in determining beforehand the possibly beneficial action of many other organic substances that are or might be available to eke out our diminishing supplies of farmyard and stable manures. At the present time, when it is planned to convert millions of acres of inferior grassland into arable, the provision of additional supplies of humusforming material becomes exceptionally important.

A potential source of supply of organic manure is the refuse of cities and large towns that is now carted away and dumped on to waste land or into the sea. The composition and production of such refuse have, inter alia, been investigated by a sub-committee of the Institute of Public Cleansing, and reported upon by $\mathrm{H}$. Edridge (1937). Samples of the refuse collected from 485,894 houses, with 2.082 million people, contained an average of 13.23 per cent of vegetable and putrescible matter, corresponding to more than one million tons of such matter contained in the estimated total of 8.3 million tons for the entire annual output of the United Kingdom. The percentage of organic matter in the refuse varied considerably with the class of dwelling; that from artisans was $9 \cdot 96$, from the middle class $15 \cdot 33$, and from the 'better' class $16 \cdot 62$. Paper averaged 1429 per cent, and rags 1.89 per cent.

The question arises, therefore, whether such refuse can be used as an organic manure, either directly or after processing. As criteria of suitability the main considerations are : contents of nitrogen, cellulose and lignin, and rate of decomposition in the soil. Although little work has been done in these directions, a few practical men have been forestalling scientific inquiry. The Corpora- tion of St. Albans, Herts, is producing material that is reported to have given good results on neighbouring farm land, and the Royal Borough of Kensington is disposing of all its refuse to a private company that is converting it into an organic manure in a plant designed to treat 250 tons a day, situated at Wood Lane, London, W. A similar plant is to be in operation at Harrow early in 1940. The process is simple: grosser solids like metal containers, glass, and paper are picked out by hand on moving belts ; the material is crushed, sprayed with a culture of nitrogen-fixing bacteria, and then allowed to ferment, aerobically and anaerobically, for sixteen days in large chambers. The product has little odour, and is a coarse brown powder containing about 30 per cent of organic matter (with about 1 per cent of nitrogen), 40 per cent of inorganic solids, and 30 per cent of moisture.

Large-scale replicated experiments to determine its manurial value were undertaken by the Rothamsted Experimental Station on a wide variety of soils at Rothamsted on kale, Woburn on sugar-beet, Tunstall (Suffolk) and Siddlesham (Sussex) on potatoes, and at High Halstow (Kent) on mangolds. The treated town's refuse (termed 'Hyganic') was compared with farmyard manure, rape-dust, and sulphate of ammonia in single and double doses. The chief interest lies in the comparison with farmyard manure at Rothamsted where, on an equal nitrogen basis, 'Hyganic' proved superior three times out of four; and at Woburn where, although the differences in terms of sugar per acre were not statistically significant, there was an advantage of 3 cwt. per acre of sugar in favour of 'Hyganic' when double dressings (l.6 cwt. nitrogen per acre) were applied. The value of the nitrogen in the manure was found to be nearly equal to one half that in sulphate of ammonia.

The results apply to the year of application only (residual effects were not examined), but they show that the organic matter in the town's refuse decomposes quickly, rendering the contained nitrogen readily available. The relatively rapid decomposition in the soil may well be associated with the beneficial effect on soil texture, which has been observed by market-gardeners and others, thus supporting Geltzer's generalization that the rate of decomposition of organic matter in a soil is directly related to the stability of the larger soil-aggregates that determine a good tilth. 